Cell Research (2003); 13(4):215-217

http://www.cell-research.com

\title{
MINIREVIEW
}

\section{Those amazing dinoflagellate chromosomes}

\author{
PETER J RIZZO \\ Department of Biology, Texas A \& M University, College Station, TX 77843, USA \\ E-mail: rizzo@bio.tamu.edu
}

\begin{abstract}
Dinoflagellates are a very large and diverse group of eukaryotic algae that play a major role in aquatic food webs of both fresh water and marine habitats. Moreover, the toxic members of this group pose a health threat in the form of red tides. Finally, dinoflagellates are of great evolutionary importance, because of their taxonomic position, and their unusual chromosome structure and composition. While the cytoplasm of dinoflagellates is typically eukaryotic, the nucleus is unique when compared to the nucleus of other eukaryotes. More specifically, while the chromosomes of all other eukaryotes contain histones, dinoflagellate chromosomes lack histones completely. There are no known exceptions to this observation: all dinoflagellates lack histones, and all other eukaryotes contain histones. Nevertheless, dinoflagellates remain a relatively unstudied group of eukaryotes.
\end{abstract}

Key words: dinoflagellates, chromosomes, histones, histone-like proteins.

\section{INTRODUCTION}

Dinoflagellate nuclei and chromosomes have been reviewed previously[1-3]. Although these reviews were published some time ago, our understanding of the ultrastructure and biochemistry of dinoflagellate chromosomes has not advanced significantly since these reviews were published, and the dinoflagellate chromosome remains enigmatic[3]. Thus the purpose of this "minireview" is to stimulate interest in dinoflagellates and their amazing chromosomes, rather than to attempt a comprehensive review of the more recent literature on the structure and composition of the dinoflagellate chromosome.

While dinoflagellates constitute a very large and diverse group of algae, they all share some common features in regard to the nucleus. To metion a few, dinoflagellates all have numerous, identically appearing chromosomes which remain condensed throughout the cell cycle, and are bounded by a rather typical eukaryotic nuclear envelope, which remains intact throughout the cell cycle[1-3]. Although some of the above features are present in other protists, dinoflagellates are the only eukaryotes known to lack histones completely. This bizarre feature, found in all dinoflagellate chromosomes, is so strange that it is often overlooked in textbooks and review articles[4].

\section{Uninucleate dinoflagellates}

Most dinoflagellates are uninucleate in that they contain one nucleus, as opposed to binucleate dinoflagellates, which contain two. The latter have an additional nucleus, present in an endosymbiont alga. The nucleus of uninucleate dinoflagellates is usually termed "dinokaryotic", due mainly to the ultrastructure of the permanently condensed, "banded" chromosomes[3]. This unique chromosome ultrastructure is the same in all dinokaryotic nuclei, in both uninucleate and binucleate dinoflagellates, with very few exceptions.

Another characteristic of dinokaryotic nuclei is that they usually contain relatively large amounts of DNA [1-3]. Indeed, some DNA content estimates are ex- 
tremely high, as in the case of Lingulodinium polyedrum (formerly known as Gonyaulax polyedra). The DNA content for this dinoflagellate was reported to be 200 $\mathrm{pg} /$ cell, as determined by a fluorometric measurement on whole cells using 3,5-diaminobenzoic acid dihydrochloride[5]. Apparently, fluorometric measurements of DNA depend heavily on the fluorescent compound used. For example, we obtained a value of 59 $\mathrm{pg} /$ nucleus as determined in L. polyedrum whole cells using 4', 6-diamidino-2-phenylindole dihydrochloride (DAPI), [Morris and Rizzo, unpublished data]. One possible reason for the different values is that the particular fluorescent compound used can give different results depending on the $\mathrm{A} / \mathrm{T}$ and $\mathrm{G} / \mathrm{C}$ content of the DNA being measured.

In any case, the presence of such large amounts of DNA in a unicellular organism brings up questions as to the function(s) of all this DNA. Clearly, most of this DNA cannot code for proteins. The possibility exists that a large part of the DNA of dinoflagellate chromosomes functions in a structural manner, but there is no evidence for, or against this speculation. Moreover, it is difficult to imagine how RNA polymerase could gain access to the DNA in the "body" of the chromosome, since the chromosomes are permanently condensed. Suggestions have been made that the main body of the chromosome is not accessible to RNA polymerase, and only the DNA strands at the periphery of the chromosome are transcribed[2].

The nuclear DNA of "typical" eukaryotes is composed of subunits called nucleosomes, which are formed when the DNA wraps around a "histone octamer" (two each of histones H2A, H2B, H3 and $\mathrm{H} 4)$. These nucleosomes are connected by 60 base pair stretches of DNA termed "linker DNA". A fifth histone (H1), "coils" these strands of nucleosomes into a 30-nm fiber[3]. This represents the basic structure of eukaryotic chromatin, which is further compacted by higher levels of folding by nonhistone proteins, and ultimately forms the metaphase chromosome. It is difficult to imagine how dinoflagellates achieved the formation of morphologically distinct chromosomes in the absence of histones, when all other eukaryotes contain histones and resulting nucleosomes. Did dinoflagellates originally contain histones and nucleosomes and somehow lost them? Or did they never contain histones, and somehow found an alternative way to condense large amounts of DNA into discrete enti- ties that we call chromosomes? These are difficult evolutionary questions to answer, and there is no consensus as to which interpretation is correct. It is worth noting however, that there is no connection between dinokaryotic chromosomes and metaphase chromosomes, polytene chromosomes, or the chromatin of the ciliate macronucleus. The dinokaryotic chromosome is unique to dinoflagellates.

\section{Dinoflagellate histone-like proteins (HLPs)}

Although the DNA of dinoflagellate chromosomes lacks histones and nucleosomes, the chromosomes do contain a small amount of basic protein that has been termed "histone-like"[1-3, 6-8]. These DNA-binding proteins are within the molecular weight range of histones, and are basic by virtue of their high lysine content. However, there is no homology between the histone-like proteins in dinoflagellates, and those of prokaryotes (and cytoplasmic organelle DNA), as well as any of the histones. These histone-like proteins are therefore unique to dinoflagellate chromosomes. The histone-like proteins in every uninucleate dinoflagellate studied thus far, reveals one or two bands, as examined by gel electrophoresis. The putative function of these proteins is still unknown, but there is some speculation that they may have a regulatory function in regard to transcription[7]. Some of these HLPs have been sequenced[7-9], and the HLPs from different dinoflagellates are similar, but not identical to one another.

\section{Binucleate dinoflagellates}

A few dinoflagellates are known to contain an endosymbiont alga which contributes a second nucleus [10-13]. These have been termed binucleate dinoflagellates. It should be stressed that the endosymbiont nucleus is within the confines of the endosymbiont plasma membrane, and does not share a common cytoplasm with the dinokaryotic nucleus. For lack of a better term, the endosymbiont nucleus is usually called the "eukaryotic" nucleus, to differentiate it from the host (dinokaryotic) nucleus. Oddly enough, the endosymbiont nucleus contains histones, but not morphologically distinct chromosomes[13]. To retain the endosymbiont condition, nuclear and cell division in the host and endosymbiont must be synchronized. Cell division is triggered by division of 
the dinokaryotic nucleus (Dr. Elenor Cox, personal communication). Subsequently, the endosymbiont nucleus pinches in two.

Recently, there has been an increase of dinoflagellate "blooms", or red tides. One such bloom was caused by the binucleate dinoflagellate Kryptoperidinium foliaceum (formerly known as Peridinium foliaceum [14]. Interestingly, on further examination, the bloom isolate was shown to lack the endosymbiont nucleus, suggesting a transient endosymbiont association[14]. Although binucleate dinoflagellates are very interesting, and also understudied, the focus of this review is on the dinokaryotic chromosome. Therefore the acquisition and maintenance of the binucleate condition will not be addressed here.

\section{REFERENCES}

1. Spector DL, Dinoflagellate nuclei. In: Spector DL Ed. Dinoflagellates. Academic Press: New York 1984:107-47.

2. Rizzo PJ, Biochemistry of the dinoflagellate nucleus. In: Taylor FJR. Ed. The biology of dinoflagellates. Blackwell Scientific: Oxford 1987:143-73.

3. Rizzo PJ. The enigma of the dinoflagellate chromosome. J Protozool 1991; 38(3):246-52.

4. Wargo MJ, Rizzo PJ. Exception to eukaryotic rules. Science 2001; 294:2477.

5. Holm-Hansen O. Algae: Amounts of DNA and organic carbon in single cells. Science 1969; 163:87-8.

6. Wargo MJ, Rizzo PJ. Characterization of Gymnodinium mikimotoi (Dinophyceae) nuclei and identification of the major histone-like protein, HGm. J Phycol 2000; 36:584-9.

7. Chudnovsky Y, Li JF, Rizzo PJ, Hastings JW, Fagan TF. Cloning, expression, and charactertization of a histone-like protein from the marine dinoflagellate Lingulodinium polyedrum (Dinophyceae). J Phycol 2002; 38:1-9.

8. Sala-Rovira M, Geraud ML, Caput D, Jacques F, SoyerGobillard M-O, Vernet G, Herzog M. Molecular cloning and immunolocalization of two variants of the major basic nuclear protein (HCc) from the histone-less eukaryote Crypthecodinium cohnii (Pyrrhophyta). Chromosoma 1991; 100:510-8.

9. Taroncher-Oldenburg G, Anderson DM. Identification and characterization of three differentially expressed genes encoding S-adenosylhomocysteine hydrolase, methionine aminopeptidase and a histone-like protein in the toxic dinoflagellate Alexandrium fundyense. Appl Environ Microbiol 2000; 66:2105-12.

10. Dodge JD. A dinoflagellate with both a mesokaryotic and eukaryotic nucleus. Protoplasma 1971; 73:145-57.

11. Tomas R, Cox ER, Steidinger KA. Peridinium balticum (Levander) Lemmermann, and unusual dinoflagellate with a mesokaryotic and an eukaryotic nucleus. J Phycol 1973; 9:91-8.

12. Farmer MA, Roberts KR. Organelle loss in the endosymbiont of Gymnodinium acidotum (Dinophyceae). Protoplasma 1990; 153:178-85.

13. Morris RL, Fuller CB, Rizzo PJ. Nuclear basic proteins from the binucleate dinoflagellate Peridinium foliaceum (Pyrrophyta). J Phycol 1993; 29:342-7.

14. Kempton JW, Wolney J, Tengs T, Rizzo P, Morris R, Tunnell J, Scott P, Steidinger K, Hymel SN, Lewitus AJ. Kryptoperidinium foliaceum blooms in South Carolina: a multi-analytical approach to identification. Harmful Algae 2002; 1:383-92. 